\section{Daily Soaps}

Protokollauszug zum Beitrag von

BOY HINRICHS

Verf.: ULRIKE BUCKARD

Übersetzt bedeutet Daily Soap Opera das tägliche (daily) spezielle Format, mit dem sich auch Werbezeit verkaufen lässt (Soap), welches stark emotionale Züge trägt (O pera).

Ausgehend von einem Boom der Talkshows Anfang der 90er Jahre in D eutschland mit hohen Einschaltquoten und bis $\mathrm{zu} 13$ verschiedenen täglichen Talksendungen veränderten sich die Einstellungen von Persönlichkeit und Gesellschaft. D as Zurschaustellen von privater Intimität ist heute schon kein Tabubruch mehr. D ie Talks dienen der Aushandlung ethischer Normen, der kommunikativen Konstruktion von Moral. Das Fernsehen wurde eine Plattform für diese Diskussionen, wobei sich der Zuschauer mit den im Talk abschließenden Normen identifizieren können soll. D urch extreme Themen aus dem Feld von Charaktereigenschaften, Körperlichkeit, Sexualität und G esundheit erlebt sich der Zuschauer als moralisches Wesen, als handelnde Instanz, was ihn vielfältig in seiner Selbstwahrnehmung beeinflusst.

Seit Mitte der 90er Jahre traten hierzulande die Soaps in den Vordergrund des Vorabendprogramms. Von neun verschiedenen Soaps haben sich vier erfolgreich etabliert und erreichen einen Marktanteil von 18 - $30 \%$ bei den 14- bis 29jährigen.
Merkmale einer Soap, die aus der populären Tradition des Erzählens kommt, nun im folgenden:

- das Ende einer Sendung ist offen (Cliffhanger)

- es laufen drei (oder mehr) Handlungsstränge parallel (Zopfdramatik)

- sie spielen in einem zielgruppenorientiertem Milieu

- haben aktuelle Bezüge (z. B. zu politischen Themen)

- Produktionskosten und -bedingungen sind niedrig/ einfach, da meist Innenaufnahmen

- es finden keine Zeitsprünge statt, alles spielt in Echtzeit

- die Soap ist unendlich fortsetzbar

Als spezielle Form einer Soap gilt die Daily Soap Opera, die sich entweder in dynastischen Kreisen (D allas, D enver), gemeinschaftlichen „ D orf-gemeinden" (Lindenstraße) oder dyadischen Beziehungen (Beziehungs-Soaps wie Marienhof, GZSZ ...) abspielt. Diese Einteilungen kommen jedoch selten in Reinform vor.

\section{Literatur}

Evermann, Jovan, 1999: D er Serien-Guide. Ein Lexikon aller Serien im deutschen Fernsehen von 1978 bis heute. Berlin.

Hinrichs, Boy, 2000: Zum Beispiel „Gute Zeiten, schlechte Zeiten" - ästhetisch defizitär und kommerziell perfekt: D as Ritual der Daily Soaps. In: D eutsches Jahrbuch für Kulturmanagement, Bd. 4, hg. v. Hinrichs, Werner / Klein, Armin (im Druck)

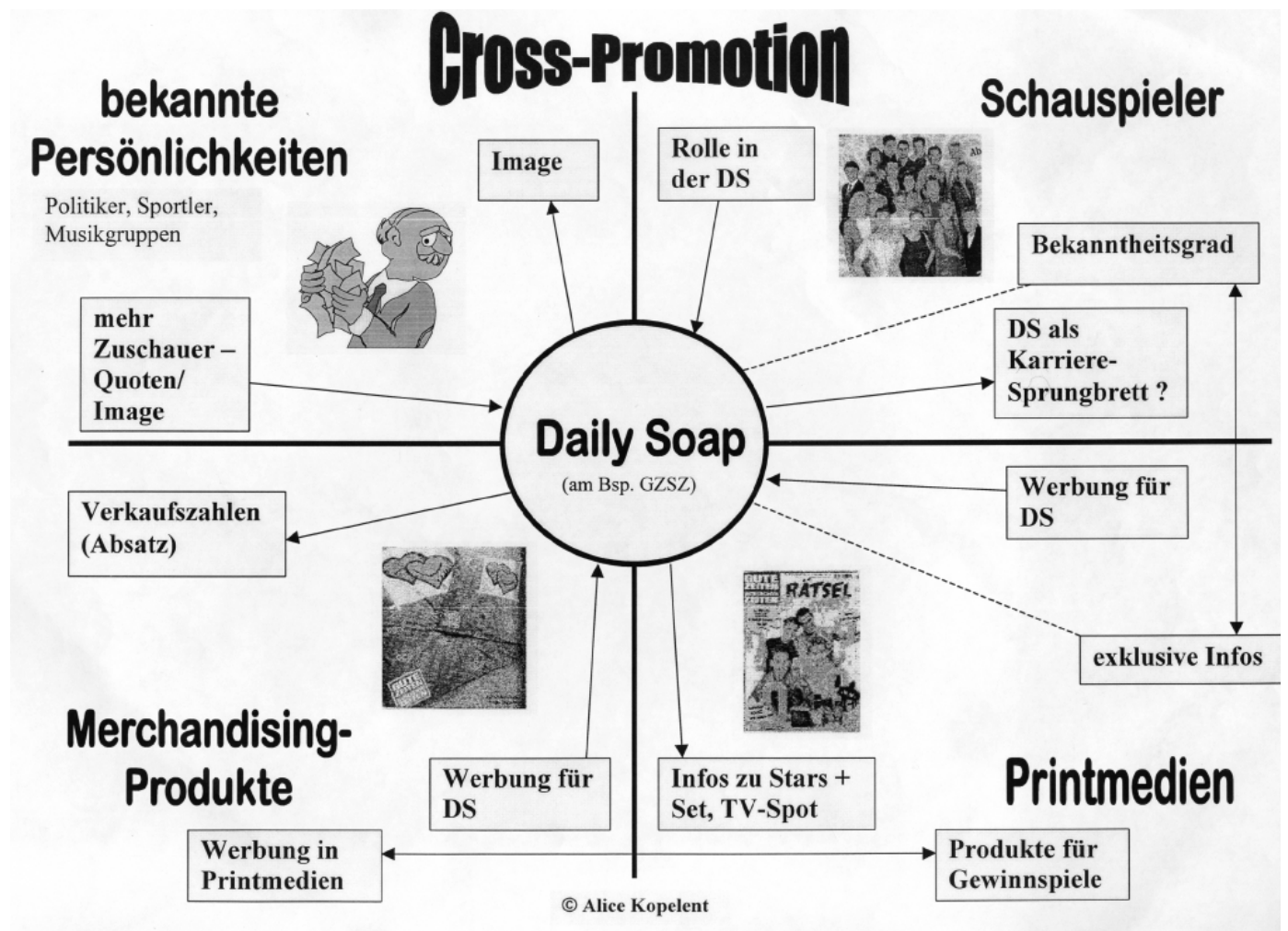

